\title{
Use of variable geometry ejector with cold store to achieve high solar fraction for solar cooling
}

\author{
M. Dennis*, K. Garzoli \\ School of Engineering, The Australian National University, Building 32, ANU, Canberra, ACT 0200, Australia
}

\section{A R T I C L E I N F O}

Article history:

Received 16 February 2010

Received in revised form

28 May 2010

Accepted 10 August 2010

Available online $\mathrm{xxx}$

Keywords:

Solar collector

Ejector

System

Thermal storage

Modelling

\begin{abstract}
A B S T R A C T
Concerns over environmental impact of heat pump cooling systems have led to a revival of solar ejector cooling systems. In order to achieve high solar fractions, the common approach is to increase the solar collector area. However, this is costly and does not provide cooling after sunset. This paper uses software modelling to examine the use of variable geometry ejectors and cold stores to increase the annual yield of an ejector system. The study concludes that a variable geometry ejector is able to increase yield by $8-13 \%$ compared to a fixed geometry ejector. However, a $46-50 \%$ increase in solar fraction is available if a $60 \mathrm{MJ}$ cold store is included compared to a fixed geometry ejector without storage and up to $63 \%$ increase in solar fraction is available if a variable geometry ejector and $60 \mathrm{MJ}$ cold store is used. Alternatively, the modelling shows how the solar collector area may be decreased if a cold store is used and this may benefit the capital and operating cost of the system.
\end{abstract}

(c) 2010 Elsevier Ltd and IIR. All rights reserved.

\section{Utilisation d'un éjecteur à géométrie variable avec accumulation thermique pour obtenir une fraction solaire élevée dans le domaine du froid solaire}

Mots clés : Capteur solaire ; Éjecteur ; Système ; Accumulation thermique ; Modélisation

\section{Introduction}

Ejector driven cooling systems powered by solar heat offer an option that appears well suited to residential use. There are no moving parts and the ejector could be cheap to manufacture. The main concerns are the poor thermal efficiency, requiring a large solar collector and moderate condensing conditions, and the inability of the system to operate after sunset without auxiliary heat.

Ejectors were originally developed for applications where a constant supply of low pressure steam was available. They were designed to run at steady state design conditions and operated reliably for long periods. This is reflected in the focus of the research effort in ejectors towards maximising the

\footnotetext{
* Corresponding author. Tel.: +64 26125 9856; fax: +64 261250506.

E-mail address: Mike.Dennis@anu.edu.au (M. Dennis).

0140-7007/\$ - see front matter @ 2010 Elsevier Ltd and IIR. All rights reserved. doi:10.1016/j.ijrefrig.2010.08.006
} 


\section{Nomenclature \\ $\mathrm{COP}_{\text {th }} \quad$ thermal coefficient of performance.}

ejector entrainment ratio and hence the $\mathrm{COP}_{\text {th }}$ of the ejector system under steady laboratory conditions. Optimising $\mathrm{COP}_{\text {th }}$ in this way reflects a desire to minimise the solar collector area and hence the capital cost of the system.

However, ejectors applied to cooling systems in varying ambient conditions are subject to widely varying generator power and condensing temperature. In this paper, the most important performance metric is annual cooling yield, measured with respect to system cost. This reflects a desire to minimise the lifecycle cost of the system.

Varying ambient conditions and fixed geometry ejectors seeking steady state conditions are not well matched. Using a fixed geometry ejector, the $\mathrm{COP}_{\text {th }}$ increases with decreasing condensing temperature and the ejector is able to operate at a lower generator temperature. However, this decreases the primary jet mass flow and thus the ejector cooling capacity remains fairly constant. Thus the fixed geometry ejector is not able to take full advantage of the cool ambient conditions in the morning.

When the design condensing temperature is exceeded, the primary jet must be driven with greater pressure and temperature to achieve the higher ejector compression ratio. However, the solar collector power may not always be available to achieve this and even when sufficient power is available, the ejector's entrainment ratio falls rapidly.

A theoretical variable area ratio ejector was shown by Sun (1996) to allow increased capacity at low condensing temperatures and smooth drop of capacity at increasing condensing temperatures. It is also able to take advantage of high generator temperatures to provide greater cooling capacity. To date, no mechanisms for variable geometry ejectors have been presented in the academic literature.

Although several researchers have examined the steady state coupling between ejectors and solar collectors (Khattab and Barakat, 2002; Huang et al., 2001), few have attempted to model ejector performance over an entire cooling season. In this study, software modelling is used to examine whether variable geometry ejectors may be more suited to dealing with varying ambient conditions than fixed geometry ejectors and whether these advantages are sufficiently promising to research into practical variable geometry ejectors.

Furthermore, many research papers are introduced using statements suggesting that there is an excellent correlation between the availability of solar radiation and the need for cooling. In this paper, the time delays between availability of solar radiation, the ambient temperature response to solar radiation and the subsequent building interior temperature response to the ambient temperature are examined. These delays can result in excessive cooling capability when it may not be needed and insufficient cooling into the evening when it may still be required. This motivates the inclusion of a cold store facility in the study.

Thus an ejector system that incorporates a variable geometry ejector coupled to a cold store should be able to operate at reasonable $\mathrm{COP}_{\text {th }}$ with high annual yield with a moderate solar collector area requirement.

This paper describes software modelling used to quantify the benefits of using variable geometry ejectors and cold storage to increase the proportion of cooling load met by solar energy in a solar cooling system (solar fraction).

\section{Variable geometry ejectors}

Ejectors based on fixed geometry are well described in the literature (Eames et al., 1995; Selvaraju and Mani, 2004; Zhu et al., 2007).

The potential advantage of variable geometry ejectors proposed by Sun who observed that fixed geometry ejectors operating at generator temperatures above that required to achieve critical condensing pressure wastes solar energy, while the ejector may fail to function if insufficient generator temperature is available. Thus the ejector only operates well at a single design point. This implies that it is challenging to couple an ejector based cooling device to a varying energy source such as a solar collector.

Sun suggested that a variable geometry ejector would require a varying area ratio and variable length in order to work optimally over a range of generator and condenser temperatures. The paper went on to propose an iterative equation to find the ejector area ratio based on condenser and generator temperature.

Although no mechanism for a variable geometry ejector has yet been presented in the literature, they appear to offer attractive improvements in performance compared to fixed geometry ejectors. This is particularly true when the condensing conditions are mild. Furthermore, a variable geometry ejector offers a more forgiving malfunction characteristic at high condensing temperatures. The design performance of the fixed and variable geometry ejectors are compared in Fig. 1. The designs use Huang's 1-D design approach (Huang et al., 1999) with refrigerant R141b. The fixed ejector has a mixing tube diameter of $12 \mathrm{~mm}$.

\section{Cold store}

The ideal cold store is a latent heat device operating at the evaporating temperature with direct heat exchange. Such a mechanism, proposed by Bi et al. (2004), uses water as the cold store medium, freezing at $8{ }^{\circ} \mathrm{C}$ forming a gas hydrate in direct contact with the refrigerant. The latent heat exchange is very high, similar to that of water and so the cold store is compact. Other advantages of this mechanism are the direct heat exchange without loss of temperature, the low cost, small component count and safety.

The ideal cold store operates at unity effectiveness and thus the results provide a best case scenario for the cold store performance (Fig. 1).

\section{Trnsys model}

A computer model of the solar ejector cooler coupled to a cooling load and cold store was constructed in the TRNSYS 

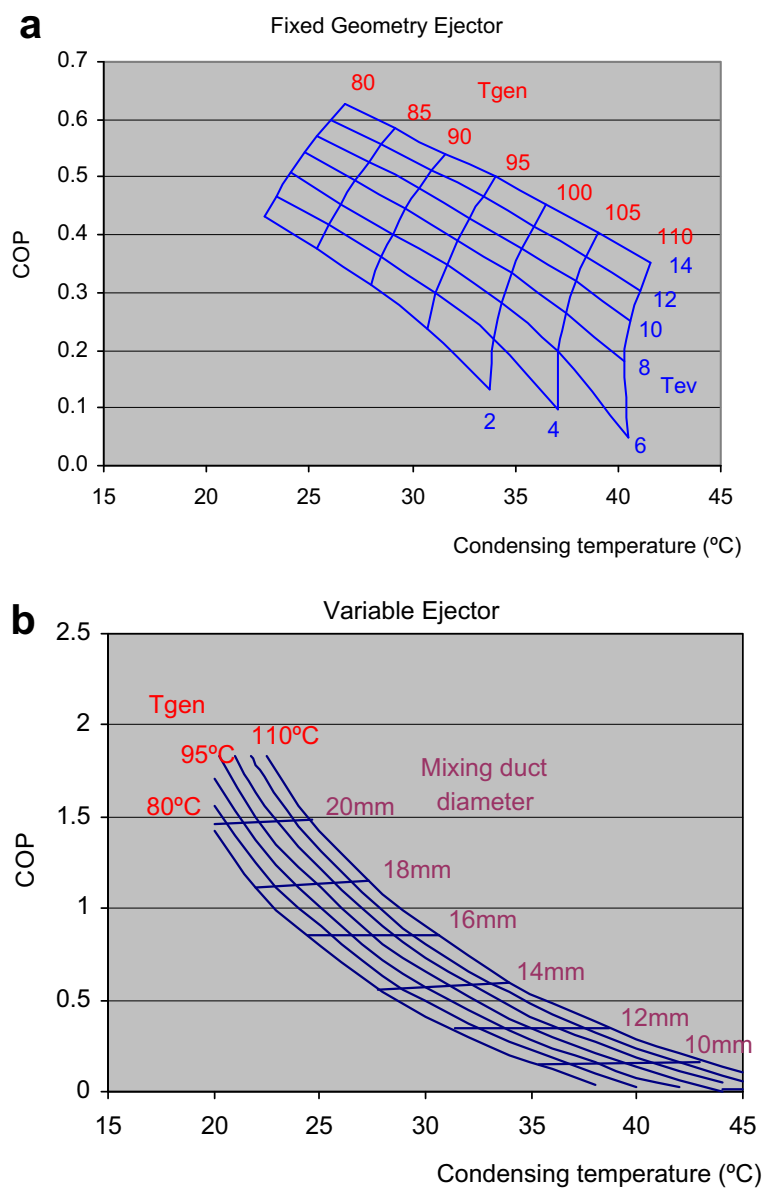

Fig. 1 - a,b. Comparison of ejector COP with fixed and variable geometries at various generator temperatures. The variable ejector is only shown at $8{ }^{\circ} \mathrm{C}$ evaporator temperature for clarity.

version 16.00.0037 environment (Klein, 2008). TRNSYS is a popular tool for evaluating the performance of solar thermal systems (Fig. 2).

The system is simplified to a number of software components which are either drawn form the standard TRNSYS libraries or written and compiled as new library components in TRNSYS custom libraries.

A standard evacuated tube solar collector model was modified for use in this simulation. The modification allowed it to operate at a constant outlet temperature by manipulating the collector mass flow rate. This collector outlet temperature (the generator temperature) was set by the ejector component. The collector azimuth was $45^{\circ}$ west providing an afternoon bias and collector slope was $20^{\circ}$ from horizontal.

Rather than modelling the detail of the complex supersonic thermodynamics of the ejector, a rule-based lookup table was used to emulate the ejector. This table was generated from a separate program which used a one dimensional thermodynamic analysis similar to that proposed by Huang. The table was implemented using the TRNSYS Dynamic Data facility in a custom TRNSYS component.

For the fixed geometry ejector the table has only the effective condensing temperature as the independent variable, since the evaporating temperature is fixed. Values for evaporating power, generator temperature and $\mathrm{COP}_{\text {th }}$ are found from the table assuming that the ejector is operating in double choking mode.

For the variable geometry ejector, the only difference was that the ejector performance lookup table has two independent variables: condensing temperature and generator temperature. The ejector component seeks to operate the ejector with the maximum generator temperature, subject to the collector being able to provide sufficient power to operate the ejector.

The ejector component was designed for $3.5 \mathrm{~kW}$ rated cooling capacity at generator, evaporator and condenser temperatures of $95{ }^{\circ} \mathrm{C}, 8{ }^{\circ} \mathrm{C}$ and $32{ }^{\circ} \mathrm{C}$ respectively using refrigerant $\mathrm{R} 141 \mathrm{~b}$. This operating point can be seen on both the fixed and variable geometry performance maps. The mixing duct diameter of the fixed ejector was $12 \mathrm{~mm}$.

The model assumes a constant $5{ }^{\circ} \mathrm{C}$ temperature increase from the ambient temperature to the condensing temperature for the air-cooled condenser. No superheat or heat exchange loss on the generator or evaporator flows was modeled in this study.

A cool store was implemented in the model such that cooling capability could be provided when insufficient solar insolation was available. The store was assumed to be a latent cool store with a transition temperature of $8{ }^{\circ} \mathrm{C}$ and capacities ranging from 0 to $60 \mathrm{MJ}$. The store was located in the conditioned room and had a heat gain coefficient of $10 \mathrm{~W} \mathrm{~K}^{-1}$.

The building load was simulated using a TRNSYS standard type 12 load component operating on energy rate control. This component produces a profile of cooling energy demand that would be required to maintain an internal temperature set point in the room. No auxiliary cooling was specified, as this would influence the room temperature and thus the cooling load. The building component simulated a small room with moderate thermal mass $\left(3 \mathrm{MJ} \mathrm{K}^{-1}\right.$ ), good insulation ( $\mathrm{UA}=220 \mathrm{~W} \mathrm{~K} \mathrm{~K}^{-1}$ ), moderate internal gains $(300 \mathrm{~W})$, a latent heat proportion of $23 \%$ and a cooling set point of $24^{\circ} \mathrm{C}$.

The simulation was run over the cooling months from October to March in Canberra, Australia (latitude $35.3^{\circ} \mathrm{S}$, longitude $149.2^{\circ} \mathrm{E}$ ), a warm dry location characterized by low humidity, high diurnal swings in ambient temperature and daily maximum ambient temperatures in the range of $20-45^{\circ} \mathrm{C}$. The simulation time-step was set to $6 \mathrm{~min}$ to capture the solar collector dynamics.

Performance is defined by the effective solar energy contribution to the total cooling energy demand (solar fraction). This solar fraction may come from either the ejector or the cool store. From the load perspective, there were periods when either:

- The load was met entirely by the ejector with some spare capacity

- The load was met only partly by the ejector

- The load was met partly by the ejector and partly by the store

- The load was met entirely by the store

- The load was met only partly by the store

- The load was not met at all 


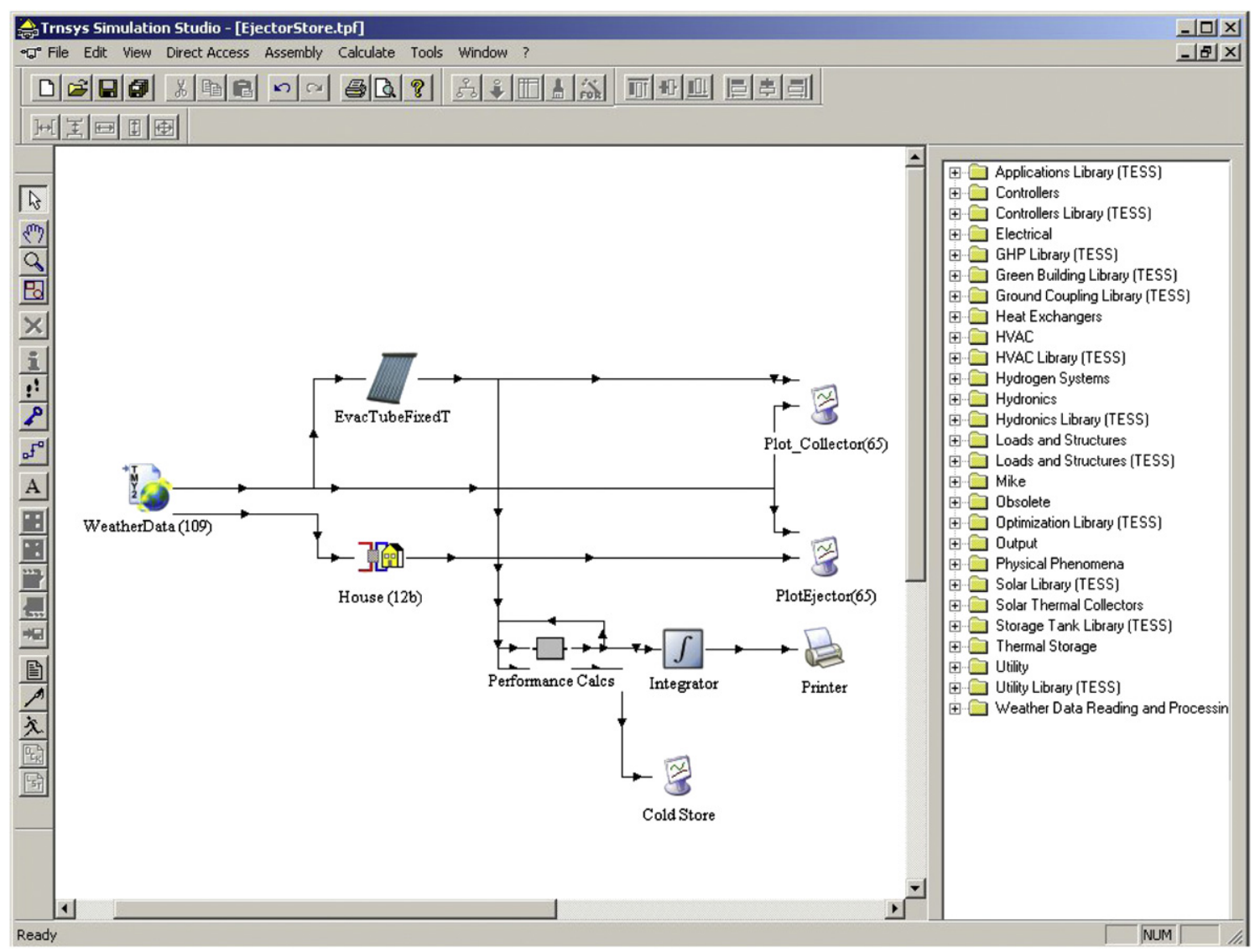

Fig. 2 - The TRNSYS simulation studio.

From the ejector perspective, there were periods where:

- The ejector's output contributed entirely to the load, with some excess

- The ejector's capacity was insufficient to meet the load

- The ejector had cooling capacity but there was no load or storage capacity

- The ejector had cooling capacity but there was no load. However, storage was available

The results were categorized within a post-processing component in TRNSYS and provided the basis for a detailed understanding of the ejector system performance.

\section{Simulation results}

\subsection{No cold storage}

With no energy storage, both fixed and variable ejector systems had poor solar fractions, $4 \%$ and $17 \%$ respectively. The variable geometry ejector consistently enabled about $13 \%$ higher solar fraction unless the collector was large in which case the advantage fell to $8 \%$ (Fig. 3).

However, the simulation also predicts that the ejector has a large amount of cooling capacity that is not being used. For the fixed ejector, that amounts to four times the annual load energy for a large collector and twice the equivalent load for a small collector. The wasted capacity is even greater with the variable geometry ejector, ranging from multiples of 12.4 to 4.9 of the load energy for large and small collectors respectively. Further breakdown of this excess capacity reveals that most of it comes about when no cooling load is required (labeled XS2) but there is still sufficient solar radiation to operate the ejector. The variable geometry ejector is best able to take advantage of high insolation and coincident cool condensing temperature by using a larger mixing duct diameter. Nevertheless, this cooling capacity is wasted.

Thus, the variable geometry ejector provides about double the excess cooling capacity that the fixed ejector provides and one might expect it to benefit most from energy storage such that this extra capacity, due to load timing mismatch, might be available for later use.

A much smaller amount of excess capacity is available when the ejector is satisfying the load (labeled XS1), presumably at times when the ambient temperature is low but cooling demand remains into the evening due to the thermal inertia of the house.

\subsection{Varying cold store capacity}

As energy storage capacity was increased, both of the ejector designs showed increased solar fractions (Fig. 4). For a large store of $60 \mathrm{MJ}$, equivalent to nearly $5 \mathrm{~h}$ of cooling at the 

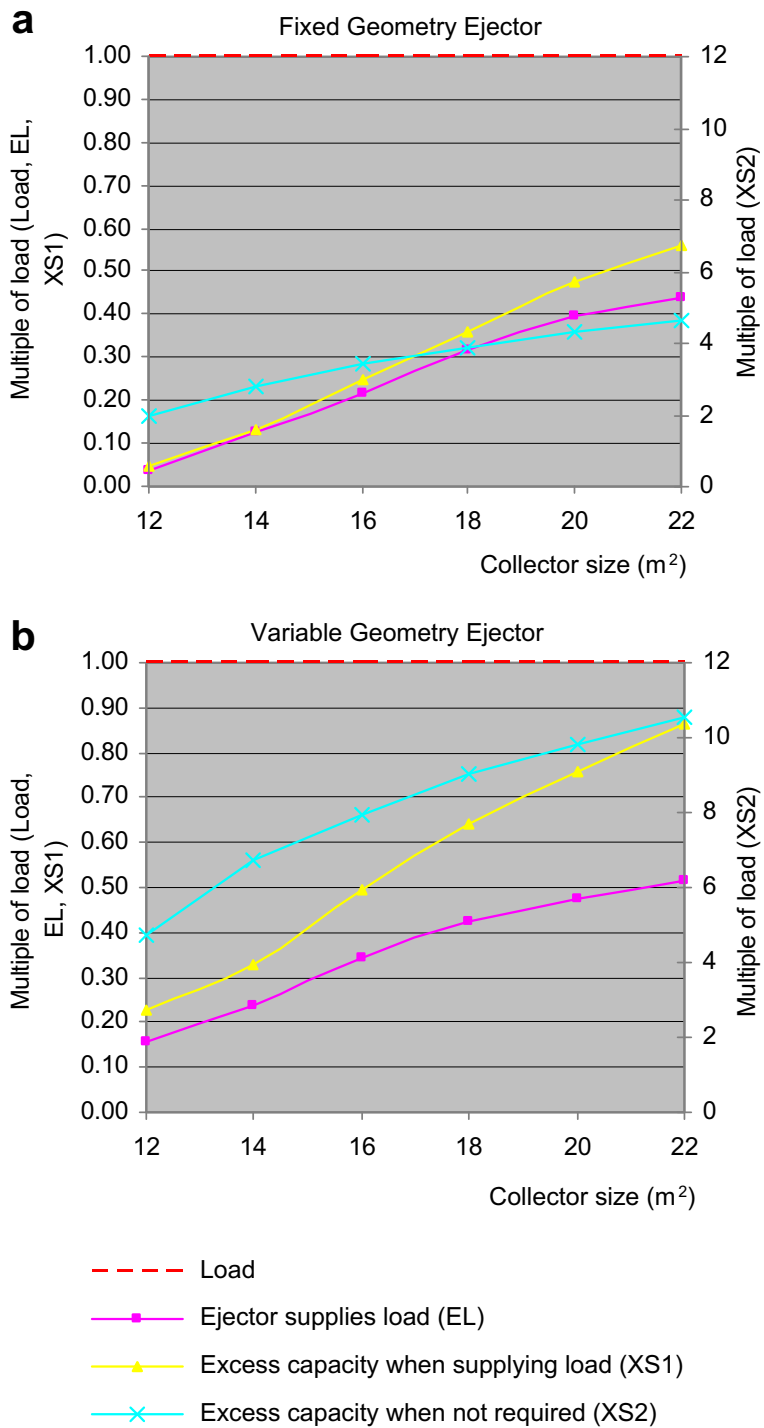

Fig. 3 - a,b. Proportions of the load that are satisfied by the ejector and the store for a range of collector areas.

ejector's $3.5 \mathrm{~kW}$ rated capacity, an increase in solar fraction of 46-50\% was shown over a typical year for the fixed ejector. This increased ability of the ejector system to meet the load was approximately consistent across all collector sizes simulated.

However, upon closer inspection of the cooling demand data, the cooling loads are concentrated to periods of short duration and high demand on hot days. This is a reflection of the characteristics of the weather data in the model. This suggests that the variable ejector operates the store at full store capacity most of the time such that the remaining $10 \%$ solar fraction would require a very large store to achieve. For a practical system, it would be impractical to achieve very high solar fractions for a solar ejector system with storage. This is a common characteristic amongst many types of solar systems.

Since a solar system is typically sized to have over $50 \%$ solar fraction, a very large collector would be required to operate the fixed ejector satisfactorily under the simulated a

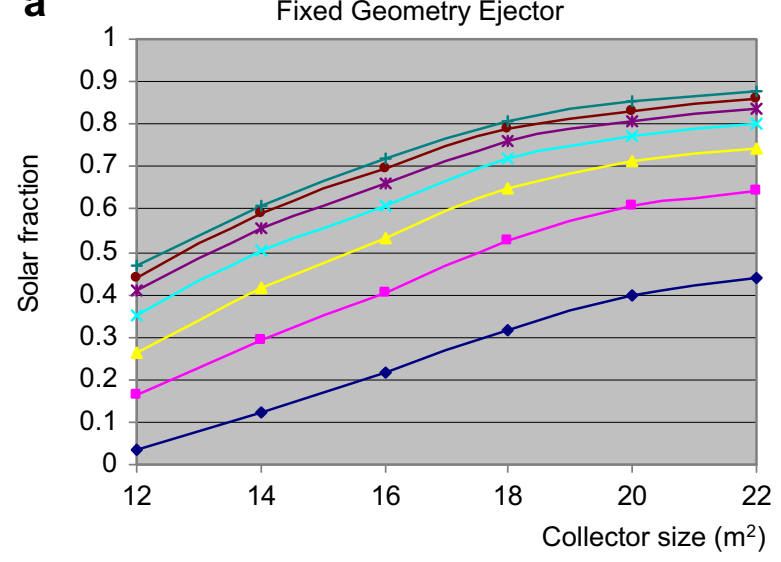

b Variable Geometry Ejector

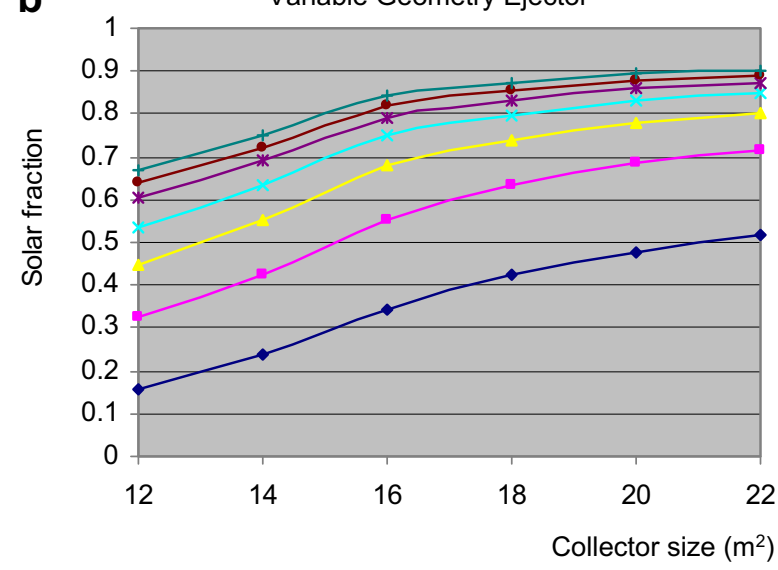

$\longrightarrow$ No Store $\longrightarrow-10 \mathrm{MJ}$ Store $-20 \mathrm{MJ}$ Store
$\rightarrow$ 30MJ Store $\rightarrow-40 \mathrm{MJ}$ Store $\longrightarrow 50 \mathrm{MJ}$ Store
$\longrightarrow$ 60MJ Store

Fig. 4 - a,b. Solar fractions of ejector systems with and without storage for a range of collector areas.

conditions. However, the use of the large store enables the solar fraction to reach $72 \%$ using only $16 \mathrm{~m}^{2}$ of collector. Thus there is a balance between the size of the solar collector and the capacity of the energy store.

The fixed ejector with a small store was unable to fully utilize the store as indicated by the low solar fraction. The collector is undersized for all but the largest storage capacities and the solar fraction is low. The store is better utilized when the solar collector is larger.

The store also benefits the variable geometry ejector, and to a greater extent. The gain in solar fraction is around $55 \%$, falling to $40 \%$ as the collector size increases. Since the variable geometry ejector has higher performance and is also better able to utilize the store, a variable geometry ejector provides a solar fraction of 0.84 using $16 \mathrm{~m}^{2}$ of collector, or match the fixed geometry ejector's performance using only $13 \mathrm{~m}^{2}$ of collector. The characteristics associated with the store utilisation previously mentioned follow the same trends for the variable geometry ejector with a smaller collector. 
The variable geometry ejector demonstrated greatest advantage by retaining some operation at high condensing temperature and a somewhat lesser advantage by increasing utilisation of the store for evening cooling.

In order to satisfy as much of the load as possible using the ejector/store system, a large store coupled with a large collector would be best. A large collector allows an ejector to directly satisfy a load and thus become less reliant on the store. In this case, large stores provide a marginal advantage over smaller stores. If the solar collector is small, the store plays an important role in meeting the load and a large store is helpful.

Surface plots of the solar fraction as a function of the collector area and store capacity clearly show the improvement in performance from the variable ejector design (Fig. 5).

These charts can readily be generated for any ejector system and serve as a useful starting point for designing a solar ejector system with cold storage capability. Furthermore, it is possible to overlay the total cost of solar collector and cold store such that a design solar fraction might be achieved at the lowest cost. At the present time, no cost data is
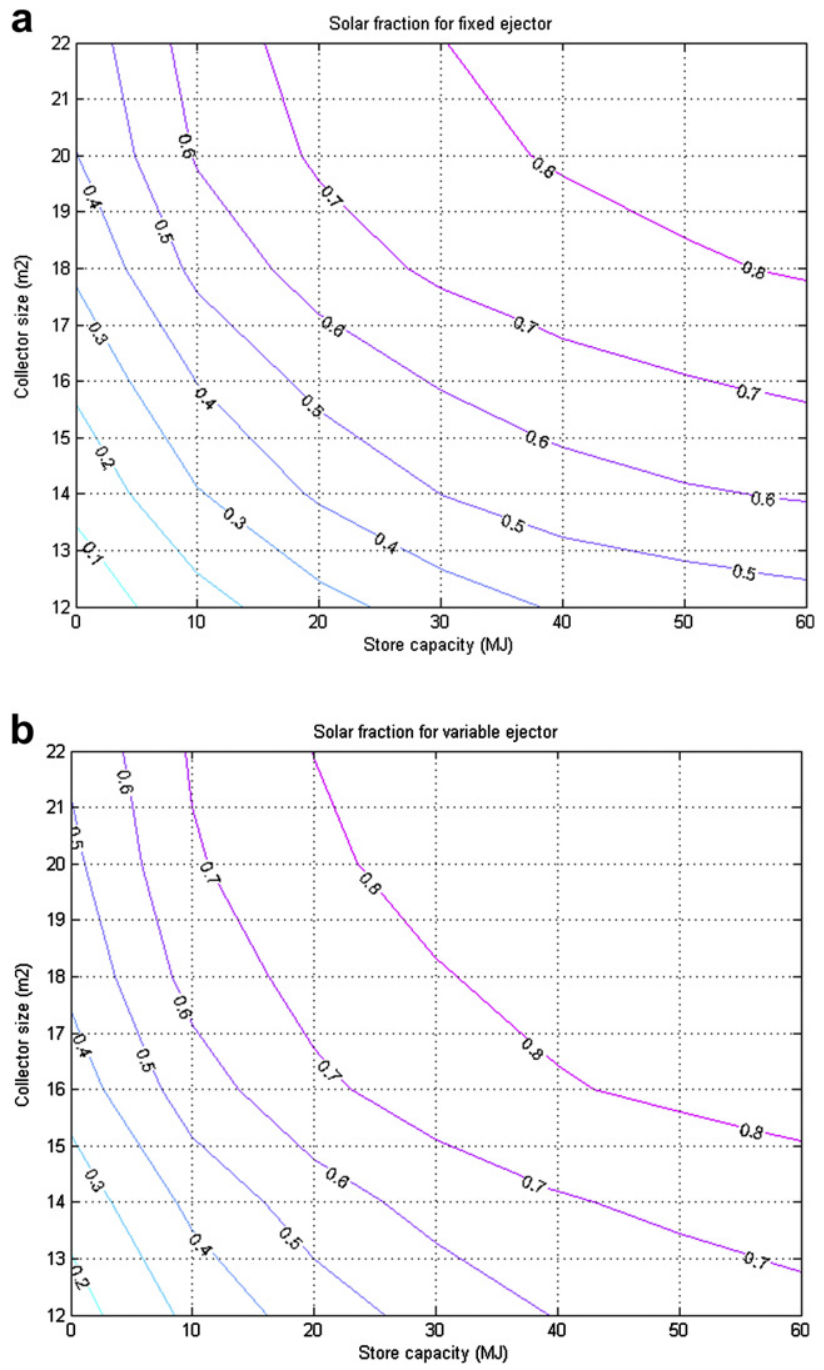

Fig. 5 - a,b. Design plot that could be used to specify the collector area for a desired solar fraction for fixed and variable geometry ejector systems with storage. available for elevated temperature latent cold store technology or for variable geometry ejector technology.

\section{Discussion}

This study has been conducted with a narrow scope. It is acknowledged that the fixed geometry ejector was not optimised for the characteristics of the climate. Indeed, an ejector's annual yield is a function of the timing and duration of condensing conditions relative to available insolation, a function of climate.

There are other approaches to solving the problem of servicing night time cooling loads. One option would be to store cold in the thermal mass of the house. This would be a low cost solution but would not be suitable for many house constructions. Also, the thermal losses from a building fabric are much higher than losses from an insulated cold store.

A second option would be to operate a hybrid electric heat pump/solar ejector system as proposed by Sokolov and Hergshal (1993) This removes the need for cold storage but would reduce the solar fraction of the ejector system by the amount that the store had provided. The system operates as a conventional electric heat pump when solar energy is unavailable.

Furthermore, the study has assumed that, due to the low $\mathrm{COP}_{\text {th }}$ of the ejector system, cold storage would be more appropriate than storage of high temperature heat as a mechanism for providing cooling into the evening. The study has also limited the scope to variable ejectors with only a variable secondary duct whereas it may be possible to vary the primary jet throat also.

\section{Conclusion}

This TRNSYS modelling of the delays between peak solar radiation, peak ambient temperature and peak indoor temperature suggest that solar ejector cooling systems are not as well suited to building cooling. This is indicated by low annual solar fractions despite large solar collector areas.

A hypothetical variable geometry ejector provides 8-13\% higher solar fraction over a fixed geometry ejector, but this alone is insufficient to achieve acceptable solar fraction for a real system at moderate sized collectors.

However, with the addition of cold energy storage, a reasonable compromise between collector area, store capacity and solar fraction can be achieved. If a $70 \%$ solar fraction is desired and a solar collector area of $20 \mathrm{~m}^{2}$ is available, a fixed ejector system would require $18 \mathrm{MJ}$ of cold store capacity whereas a variable geometry ejector would require only $12 \mathrm{MJ}$ of cold store capacity. Alternatively, if a $60 \mathrm{MJ}$ cold store is available, the fixed ejector system could operate at $70 \%$ solar fraction using a reduced solar collector area of $15.6 \mathrm{~m}^{2}$ whereas a variable ejector system could operate using a solar collector area of only $12.8 \mathrm{~m}^{2}$.

As the variable geometry ejector and cold store costing becomes available, system designers will readily be able to achieve a target solar fraction with an ejector cooler coupled to a solar collector and cold store with minimal cost. 


\section{R E F E R E N C E S}

Bi, Y., Guo, T., Zhu, T., Fan, S., Liang, D., Zhang, L., 2004. Influence of volumetric-flow rate in the crystallizer on the gas-hydrate cool-storage process in a new gas-hydrate cool-storage system. Applied Energy 78 (1), 111-121.

Eames, I., Aphornratana, S., Haider, H., 1995. A theoretical and experimental study of a small-scale steam jet refrigerator. Int. J. Refrigeration 18, 376-386.

Huang, B., Chang, J., Wang, C., Petrenko, V., 1999. A 1D analysis of ejector performance. Int. J. Refrigeration 22, 354-364.

Huang, B., Petrenko, V., Samofatov, Y., Shchetinina, N., 2001. Collector selection for solar ejector cooling system. Solar Energy 71 (No. 4), 269-274.
Khattab, N., Barakat, M., 2002. Modeling the deisgn and performance characteristics of solar steam jet cooling for comfort air conditioning. Solar Energy 73, 257-267.

Klein, S., 2008. TRNSYS 16, Solar Energy Laboratory. University of Wisconsin, Madison, USA.

Selvaraju, A., Mani, A., 2004. Analysis of a vapour ejector refrigeration system with environmentally friendly refrigerants. Int. J. Thermal Sciences 43, 915-921.

Sokolov, M., Hergshal, D., 1993. Optimal coupling and feasibility of a solar powered year round ejector air conditioner. Solar Energy 50 (No.6), 507-516.

Sun, D., 1996. Variable geometry ejectors and their applications in ejector refrigeration systems. Energy 21 (No. 10), 919-929.

Zhu, Y., Cai, W., Wen, C., Li, Y., 2007. Shock circle method for ejector performance evaluation. Energy Conversion and Management 48, 2533-2541. 